\title{
Time-Resolved Raman Spectroscopy and Matrix Isolation Studies of Anti-Syn Photoisomerization in Metal Carbonyl Carbenes
}

\author{
A. Denise Rooney, ${ }^{* \dagger}$ John J. McGarvey, ${ }^{*}$ and Keith C. Gordon ${ }^{\ddagger}$ \\ School of Chemistry, The Queen's University of Belfast, Belfast BT9 5AG, Northern Ireland
}

Received June 13, $1994^{\otimes}$

\begin{abstract}
Photoinduced anti-syn isomerization in tungsten carbonyl carbenes, $(\mathrm{CO})_{5} \mathrm{~W}=\mathrm{C}(\mathrm{OR}) \mathrm{R}^{\prime}$, [1 with $\mathrm{R}=\mathrm{Me}, \mathrm{R}^{\prime}=\mathrm{Me} ; 2$ with $\mathrm{R}=\mathrm{Me}, \mathrm{R}^{\prime}=p$-Tolyl ; 3 with $\mathrm{R}=\mathrm{Et}, \mathrm{R}^{\prime}=\mathrm{Ph}$ ] brought about by irradiation in the MLCT absorption region has been investigated by laser flash photolysis coupled with transient absorbance and time-resolved resonance Raman spectroscopy (TR $\left.{ }^{3} \mathrm{~S}\right)$. The studies, carried out in solution in solvents of varying polarity, have been supplemented by matrix isolation studies using UV-vis and IR detection. Pulsed irradiation in the MLCT absorption region of $1-3$ results in the formation within the pulse risetime of the syn isomer from the ground state (anti) form, followed by thermal relaxation/isomerization back to the ground state. In all three complexes the transient lifetimes increase with increasing solvent polarity falling in the range $120 \mu \mathrm{s}-3 \mathrm{~ms}$ for 1 and 1-2 orders of magnitude shorter for 2 and 3. Growth and decay of the syn isomer were also monitored by $\mathrm{TR}^{3} \mathrm{~S}$. For 1 , bands in the Raman attributable to modes of the carbene group showed little change in frequency between the anti and syn isomers. In the case of the anti forms of 2 and 3 , a band near $1235 \mathrm{~cm}^{-1}$ attributable to $v\left(\mathrm{C}_{\text {carbene }}-\mathrm{OR}\right)$ shifts to $c a .1270 \mathrm{~cm}^{-1}$ in the spectra of the syn isomer. The differences beween 1,2 and 3 in respect of both vibrational spectra and rates of isomerization are discussed in relation to the possible influence on electronic stabilization of reorientation of the $R^{\prime}$ group which accompanies anti-syn transformation. Comparison of the anti-syn photoisomerization of 1 in an argon matrix with that of $4\left(R=M e, R^{\prime}=P h\right)$ shows that the process is photoreversible only in the case of 1 .
\end{abstract}

\section{Introduction}

The existence of anti and syn isomers (eq 1) in solution for metal carbenes of the type $[M]-C(X R)\left(R^{\prime}\right), X=0, N$,<smiles>[R][X]C([R])C(=O)OC(=O)[O-]</smiles><smiles>[R][X]C([R])=C(C)C(=O)O</smiles>

$\mathrm{S}$, has been established since the NMR studies carried out on chromium pentacarbonyl carbenes. ${ }^{1}$ The isomers arise as a result of inhibited rotation about the $\mathrm{C}-\mathrm{X}$ bond in which the partial double bond character is due to the $\pi$ interaction between the lone pair of electrons on the heteroatom and the carbene carbon $2 p_{\mathrm{z}}$ orbital. The energy difference $E_{\text {syn }}-E_{\text {anti }}$ between the two isomers is very dependent on the heteroatom $(\mathrm{N}>\mathrm{O}>$ $\mathrm{S})$, the $\pi$ donating ability of $\mathrm{R}^{\prime}$, steric interactions and the solvent environment. Which isomer is energetically the more favored will depend on the steric demands of the complex. However, in complexes of the type $(\mathrm{CO})_{5} \mathrm{WC}(\mathrm{OR})\left(\mathrm{R}^{\prime}\right)$, which are studied here, the anti isomer predominates. ${ }^{2}$

\footnotetext{
† Present address: Department of Chemistry, St. Patrick's College, National University, Maynooth, Ireland.

₹ Present address: Chemistry Department, University of Otago, Dunedin, N. Zealand.

$\otimes$ Abstract published in Advance ACS Abstracts, November 1, 1994

(1) Kreiter, C. G.; Fischer, E. O. Angew. Chem. Int. Ed. Engl. 1969, 8,761 .
}

The electronic absorption spectra of $(\mathrm{CO})_{5} \mathrm{WC}(\mathrm{OR})$ $\left(R^{\prime}\right)$ generally exhibit two bands, a higher energy $L F$ transition, assigned in one-electron terms as $\left(\mathrm{b}_{2}^{2}\right) \rightarrow$ $\left(2 \mathrm{a}_{1}{ }^{1}, \mathrm{~b}_{2}{ }^{1}\right)$ in the assumed ${ }^{3}$ local $C_{2 v}$ symmetry of the carbene group, and a lower energy MLCT transition, assigned as $\left(b_{2}^{2}\right) \rightarrow\left(3 a_{1}{ }^{1}, b_{2}{ }^{1}\right)$. The latter transition formally promotes electron density into the carbene carbon $2 \mathrm{p}_{\mathrm{z}}$ orbital. The photochemistry associated with the LF transition involves $\mathrm{CO}$ dissociation. ${ }^{3}$ Until recently photoexcitation within the MLCT region has been less extensively investigated. ${ }^{4}$

Previous work from this laboratory on the photochemistry of $(\mathrm{CO})_{5} \mathrm{WC}(\mathrm{OMe})(\mathrm{Ph})$, the first time-resolved resonance Raman $\left(\mathrm{TR}_{3}\right)$ study on an organometallic complex, ${ }^{5}$ noted that LF excitation resulted in the formation of a transient with a lifetime in the $\mu$ s range. Originally it was believed that this was a 16-electron species arising from CO loss. Subsequent work on this same complex in a matrix by Stufkens et al. demonstrated that irradiation into the MLCT band of the complex resulted in anti to syn photoisomerization, ${ }^{2}$ according to eq 1 . Furthermore, these workers showed that irradiation into the higher energy LF band also resulted in the same photoisomerization, apparently

(2) Servaas, P. C.; Stufkens, D. J.; Oskam, A. J. Organomet. Chem. $1990,390,61$.

(3) Foley, H. C.; Strubinger, L. M.; Targos, T. S.; Geoffroy, G. L. J. Am. Chem. Soc. 1983, 105, 3064; Fong, L. K.; Cooper, N. J. Ibid. 1984 $106,2595$.

(4) Poirreau, D.; Geoffroy, G. L. Adv. Organomet. Chem. 1985, 24, 249.

(5) Bell, S. E. J.; Gordon, K. C.; McGarvey, J. J. J. Am. Chem. Soc. $1988,110,3107$ 
arising as a result of efficient radiationless decay from the initially populated LF state into the lower lying MLCT state. The transient species originally reported ${ }^{5}$ in the $\mathrm{TR}_{3}$ studies in solution was identified ${ }^{2}$ as the $s y n$ isomer of $(\mathrm{CO})_{5} \mathrm{WC}(\mathrm{OMe})(\mathrm{Ph})$ as observed in the matrix experiments. More recently we have reported the observation of a photogenerated transient syn isomer in the related carbene complex $(\mathrm{CO})_{5} \mathrm{WC}(\mathrm{OEt})\left(\mathrm{SiPh}_{3}\right){ }^{6}$

The primary aim of the present work has been to carry out a comparative study of the photoisomerization of $(\mathrm{CO})_{5} \mathrm{WC}(\mathrm{OR})\left(\mathrm{R}^{\prime}\right)$ complexes in solution, using the methods of flash photolysis and $\mathrm{TR}_{3}$ spectroscopy, and in an argon matrix, using IR and UV/vis spectroscopic detection. The following complexes, containing both aryl and alkyl substituents have been investigated: $(\mathrm{CO})_{5} \mathrm{WC}(\mathrm{OMe})(\mathrm{Me}), \mathbf{1},(\mathrm{CO})_{5} \mathrm{WC}(\mathrm{OMe})\left(p-\mathrm{C}_{6} \mathrm{H}_{4} \mathrm{CH}_{3}\right), 2$, and $(\mathrm{CO})_{5} \mathrm{WC}(\mathrm{OEt})(\mathrm{Ph}), 3$. The results are considered in relation to the earlier studies ${ }^{5}$ of the Fischer carbene, $(\mathrm{CO})_{5} \mathrm{WC}(\mathrm{OMe})(\mathrm{Ph}), 4$.

\section{Experimental Section}

Flash photolysis experiments were carried out using either a Nd/YAG laser (355 nm, $10 \mathrm{~ns}$ pulse width, ca. 10-30 mJ pulse $\mathrm{e}^{-1}$ ) or a $\mathrm{XeCl}$ excimer laser ( $308 \mathrm{~nm}, 30 \mathrm{~ns}$ pulse width, up to $40 \mathrm{~mJ}$ pulse ${ }^{-1}$ ). Both systems have previously been described in detail. ${ }^{7,8}$ For resonance Raman studies the $\mathrm{Nd} /$ YAG laser coupled with a Raman shifter was used for recording the transient spectra and an argon ion laser for the ground state spectra. ${ }^{5,9}$ Two-color $\mathrm{TR}^{3}$ experiments were carried out at the Central Laser Facility, Rutherford Appleton Laboratory (RAL), using excimer and excimer-pumped dye lasers as pump and probe sources respectively. The matrix isolation experiments were carried out at the University of York and the apparatus has been described in detail elsewhere. ${ }^{10}$ The samples were deposited on $\mathrm{a} \mathrm{BaF}_{2}$ window which was cooled to $12-20 \mathrm{~K}$ by an Air Products CS202 closed-cycle Displex refrigerator. The complexes were sublimed onto the window from a tube, concurrent with the gas stream that entered the vacuum shroud from a separate inlet.

Matrices were photolysed using a $300 \mathrm{~W}$ Xe arc (ILC, model $302 \mathrm{UV}$ ) with appropriate filters. The IR spectra were recorded on either a Mattson Sirius FTIR or Mattson Research Series FTIR spectrometer with a $\mathrm{PbS}$ detector and a $\mathrm{KBr}$ beam splitter $\left(4000-450 \mathrm{~cm}^{-1}\right)$ or a CsI beam splitter $(4000-200$ $\mathrm{cm}^{-1}$ ). The spectrometer was continuously purged with $\mathrm{CO}_{2-}$ free dry air. The spectra were recorded as the average of 128 scans with $1 \mathrm{~cm}^{-1}$ resolution (25K data points). The UV/vis spectra were recorded on a Perkin-Elmer Lambda $7 \mathrm{G}$ spectrometer. The complexes and their deuteriated analogs were synthesized by standard literature procedures. ${ }^{11}$

For the flash photolysis experiments the samples were dissolved in the appropriate solvent in a $1 \mathrm{~cm}$ path length quartz cuvette. The absorbances of the solutions were in the range $0.5-1.0$ at the excitation wavelength. The solutions were either purged with argon or degassed by several freezepump thaw cycles to $10^{-4}$ mbar before back filling to $1 \mathrm{~atm}$ of argon. For the transient resonance Raman spectra the argonpurged samples were circulated through a quartz capillary (ca.

(6) Rooney, A. D.; McGarvey, J. J.; Gordon, K. C.; McNicholl, R-A.; Schubert, U.; Hepp, W.; Organometallics 1993, 12, 1277.

(7) Bell, S. E. J.; Gordon, K. C.; McGarvey, J. J. Inorg. Chem. 1988 27,4003 .

(8) Belt, S. T.; Grevels, F-W.; Klotzbucher, W.; McCamley, A.; Perutz, R. N. J. Am. Chem. Soc. $1989,111,8373$.

(9) Bell, S. E. J.; Gordon, K. C.; McGarvey, J. J. J. Raman Spectrosc. $1989,20,105$.

(10) Haddleton, D. M.; McCamley, A.; Perutz, R. N. J. Am. Chem. Soc. 1988, 110,1810 .

(11) (a) Villemin, D. J. Chem. Ed. 1987, 64, 183. (b) Schubert, U. Fischer, E. O. Liebigs Ann. Chem. 1975, 393.
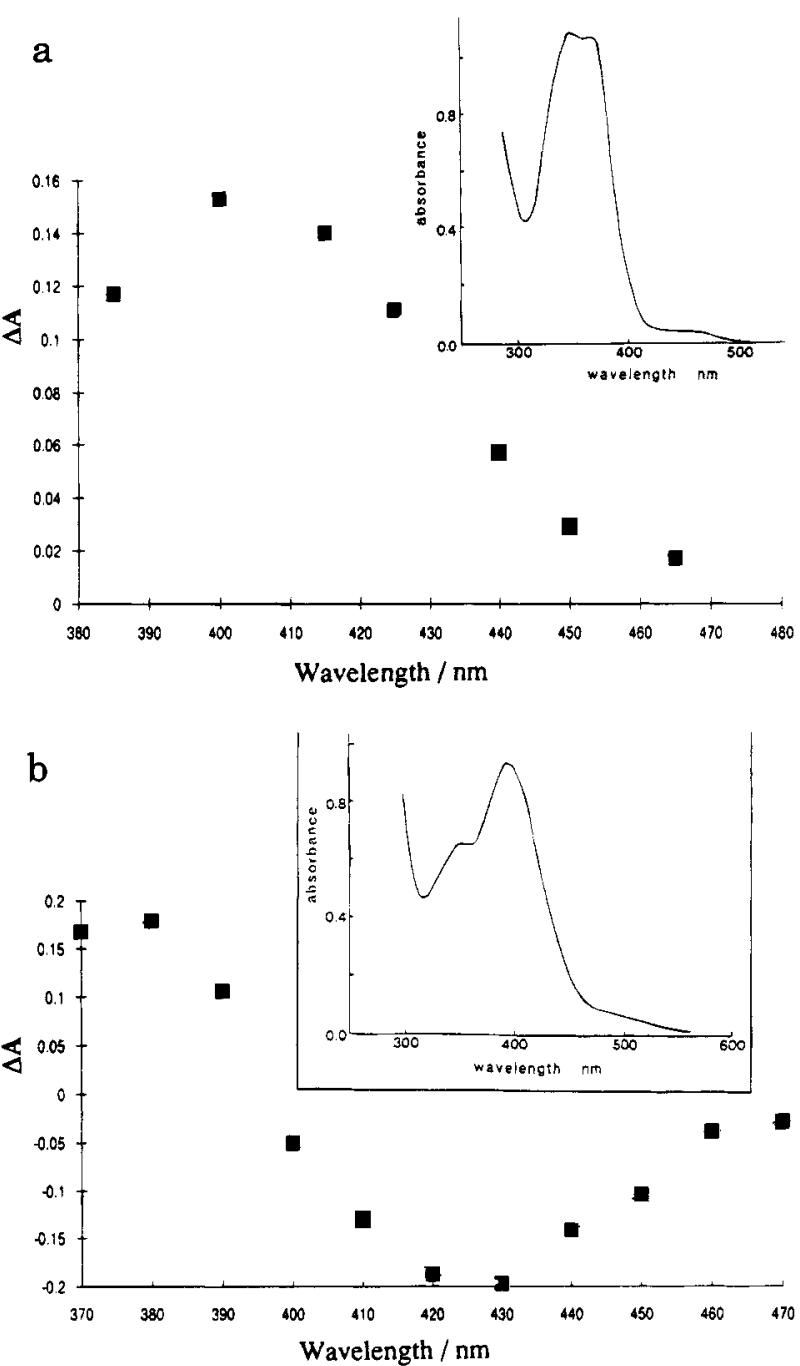

Figure 1. Transient absorbance difference $(\Delta A)$ spectra recorded following flash photolysis at $354.7 \mathrm{~nm}$ of (a) $(\mathrm{CO})_{5} \mathrm{~W}=\mathrm{C}\left(\mathrm{OCH}_{3}\right) \mathrm{CH}_{3}$ and (b) $(\mathrm{CO})_{5} \mathrm{~W}=\mathrm{C}\left(\mathrm{OCH}_{2} \mathrm{CH}_{3}\right) \mathrm{C}_{6} \mathrm{H}_{5}$. Solution concentrations were ca. $10^{-3} \mathrm{~mol} \mathrm{dm}-3$ in $\mathrm{CH}_{2} \mathrm{Cl}_{2}$ in both cases. Insets: corresponding ground electronic absorption spectra.

$1 \mathrm{~mm}$ i.d.) at a rate which ensured that each laser pulse irradiated a fresh volume of solution, thus minimizing sample decomposition in the laser beam.

\section{Results}

(a) Flash Photolysis. Complex 1 exhibits two absorption bands at $350 \mathrm{~nm}$ (LF) and $370 \mathrm{~nm}$ (MLCT) in cyclohexane solution. Irradiation of a solution of 1 in dichloromethane at $355 \mathrm{~nm}$ resulted in a rise in absorption in the range $390-460 \mathrm{~nm}$ occurring within the time resolution of the apparatus $(c a .10 \mathrm{~ns}$ ) and followed by an exponential decay to the preflash absorbance level. The maximum in the $\Delta A$ spectrum measured in $\mathrm{CH}_{2} \mathrm{Cl}_{2}$ (Figure 1a) exhibited a red shift of $c a$. $15 \mathrm{~nm}$ from the ground state absorption maximum (365 $\mathrm{nm})$. Little change was observed in the $\Delta A$ maximum with solvent. The transient lifetime however was markedly solvent-dependent (Table 1) and varied with temperature, yielding an activation enthalpy of $51 \pm 2$ $\mathrm{kJ} \mathrm{mol}^{-1}$ in cyclohexane from an Eyring plot over the range (283-328) $\mathrm{K}$.

Complex 2, with absorption bands at $354 \mathrm{~nm}$ (LF) and $410 \mathrm{~nm}$ (MLCT) in cyclohexane displayed similar tran- 
Table 1. Lifetimes ( $\mu$ s) of Syn Isomers of Tungsten Carbenes in Solution ${ }^{a}$

\begin{tabular}{lccl}
\hline \multicolumn{1}{c}{ solvent } & $\begin{array}{c}(\mathrm{CO})_{5} \mathrm{WC}- \\
(\mathrm{OMe}) \mathrm{Me}\end{array}$ & $\begin{array}{c}(\mathrm{CO})_{5} \mathrm{WC}- \\
(\mathrm{OEt}) \mathrm{Ph}\end{array}$ & $\begin{array}{l}(\mathrm{CO})_{5} \mathrm{WC}- \\
(\mathrm{OMe}) \mathrm{p}-\mathrm{tol}\end{array}$ \\
\hline hexane & $126 \pm 4$ & $4.65 \pm 0.10$ & $1.1 \pm 0.05$ \\
cyclohexane & $294 \pm 15$ & $5.0 \pm 0.2$ & $1.62 \pm 0.05$ \\
dichloromethane & $1200 \pm 100$ & $14.3 \pm 0.3$ & $3.70 \pm 0.15$ \\
methanol & $2642 \pm 211$ & $20.7 \pm 0.4$ & $6.6 \pm 0.3$ \\
acetonitrile & $3356 \pm 300$ & $23 \pm 2$ & $7.1 \pm 0.3$ \\
${ }^{a}$ Measurements at $20^{\circ} \mathrm{C}, \mathrm{ca} .10^{-3} \mathrm{~mol} \mathrm{dm}^{-3}$. &
\end{tabular}

Table 2. Principal Bands $\left(\mathrm{cm}^{-1}\right)$ in $\mathrm{CW}$ and Pulsed (Single Color) RR Spectra of Carbene Complexes

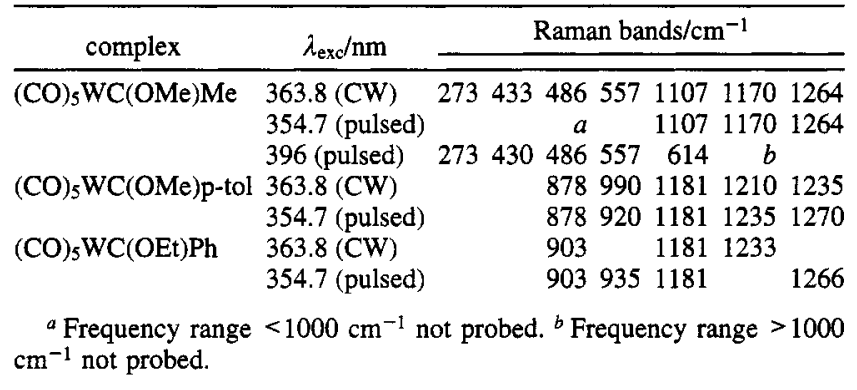

sient behavior, again showing a rise in $<10 \mathrm{~ns}$ (the response time of the experiment) in the absorbance between 370 and $390 \mathrm{~nm}$ and in this case a ground state depletion in the range $400-450 \mathrm{~nm}$. The first order transient decay was temperature- and solvent-dependent as for 1 but the lifetime was some two orders of magnitude shorter.

Irradiation at $355 \mathrm{~nm}$ of the EtO-substituted analogue, 3 , which has absorption bands at $356 \mathrm{~nm}$ (LF) and $403 \mathrm{~nm}$ (MLCT) also resulted in formation of a transient within the laser pulse risetime and with a very similar $\triangle A$ spectrum to that observed for 2 , positive over the range $370-390 \mathrm{~nm}$ and showing depletion between 400 and $460 \mathrm{~nm}$ (Figure $1 \mathrm{~b}$ ). The transient decayed exponentially as a function of temperature and solvent with a lifetime slightly longer than that of the phenyl analogue, 2 . In general, the behavior of 3 was very similar to the Fischer carbene, $(\mathrm{CO})_{5} \mathrm{WC}(\mathrm{OMe})(\mathrm{Ph}) 4$, reported in an earlier paper. ${ }^{5}$ The latter investigation has been extended in the present work by investigating the temperature dependence of the thermal isomerization of the syn back to the anti form following photogeneration by flash photolysis at $308 \mathrm{~nm}$. Measurements over the temperature range (283-328) $\mathrm{K}$ in cyclohexane solution, yielded an activation enthalpy from the Eyring plot of $37 \pm 3 \mathrm{~kJ} \mathrm{~mol}^{-1}$ for the thermal relaxation to the anti ground state.

(b) Resonance Raman spectroscopy. Principal features in the resonance Raman (RR) spectra recorded under CW-and pulsed-excitation for complexes 1 - $\mathbf{3}$ are summarized in Table 2. For complex 1 , spectra generated at either $\lambda_{\text {exc }}=363.8 \mathrm{~nm}(\mathrm{CW})$ or $355 \mathrm{~nm}$ (pulsed) in $\mathrm{CH}_{2} \mathrm{Cl}_{2}$ solution showed features at 1107,1170 and $1264 \mathrm{~cm}^{-1}$. In the lower frequency region of the $\mathrm{RR}$ spectrum, generated at $363.8 \mathrm{~nm}$ in cyclohexane as solvent , bands appeared at $277,430,486,557$ and 594 $\mathrm{cm}^{-1}$. With pulsed excitation at $396 \mathrm{~nm}$ a new band grew in at $614 \mathrm{~cm}^{-1}$. The results of a two-color timeresolved experiment carried out on the same sample are shown in Figure 2. The spectra were recorded using a pump wavelength of $351 \mathrm{~nm}$ and a probe wavelength of $406 \mathrm{~nm}$ at a series of pump-probe delays over the time range $120 \mathrm{~ns}-600 \mu \mathrm{s}$. The rate of decay which can be

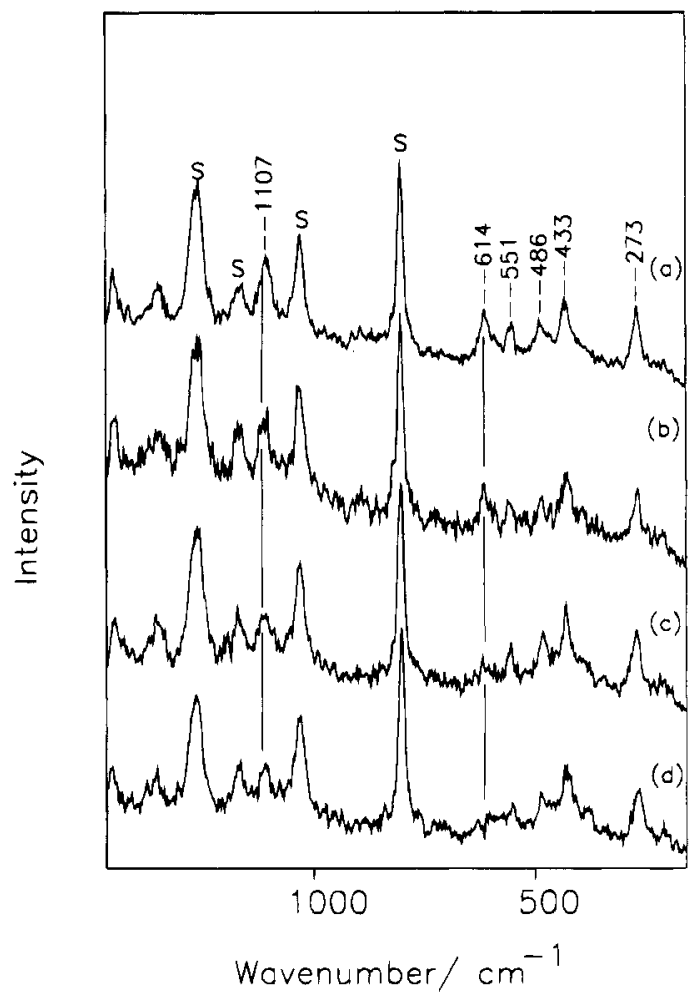

Figure 2. Two-color time-resolved resonance Raman study of $(\mathrm{CO})_{5} \mathrm{~W}=\mathrm{C}\left(\mathrm{OCH}_{3}\right) \mathrm{CH}_{3}$ in $\mathrm{C}_{6} \mathrm{H}_{12}\left(\mathrm{ca} .10^{-3} \mathrm{~mol} \mathrm{dm}^{-3}\right)$ : Pump $\lambda 351 \mathrm{~nm}$; probe $\lambda 406 \mathrm{~nm}$. Pump-probe time delays: (a) $120 \mathrm{~ns}$; (b) $100 \mu \mathrm{s}$; (c) $300 \mu \mathrm{s}$; (d) $600 \mu \mathrm{s}$.

estimated from the gradual disappearance with increasing pump-probe delay of the $614 \mathrm{~cm}^{-1}$ feature in Figure 2 is consistent with the $300 \mu$ s lifetime recorded in the flash photolysis experiments in the same solvent (Table 1). CO saturation of the solution had no measurable effect on the rate of transient decay.

The intensity of the $1107 \mathrm{~cm}^{-1}$ band relative to the solvent peak at $1028 \mathrm{~cm}^{-1}$ also changes with pumpprobe delay confirming it as a transient feature, unshifted from the ground state position. This is also the case for the band near $1264 \mathrm{~cm}^{-1}$ although the variation of band intensity is not immediately evident from Figure 2 because of an overlapping solvent feature at 1266 $\mathrm{cm}^{-1}$. However a careful comparison of the spectra from Figure 2, recorded at the shortest and longest pumpprobe delays brings out the point. The two spectra are replotted in Figure 3, along with the corresponding difference spectrum, from which the enhanced intensity of the $1264 \mathrm{~cm}^{-1}$ band at the shortest delay is evident. The decrease in intensity of both this band and that at $1107 \mathrm{~cm}^{-1}$ for the transient compared to the ground state is what would be expected from resonance enhancement considerations. The monitoring beam at 406 $\mathrm{nm}$ is more in resonance with the MLCT absorption of the transient (Figure 1a) than that of the ground state $\left(\lambda_{\max } 370 \mathrm{~nm}\right)$. The observed changes in intensity confirm that the bands observed at the short time delays are transient features, unshifted in frequency from the ground state.

In the case of complex 2 several bands also appear at the same frequencies in $\mathrm{CW}$ - $(363.8 \mathrm{~nm})$ and pulse$(355 \mathrm{~nm})$ generated spectra but additional, transient bands were observed at $920 \mathrm{~cm}^{-1}$ and $1270 \mathrm{~cm}^{-1}$ in the pulse-generated spectra. The pattern for complex 3 was very similar, with several features common to the $C W$ - 


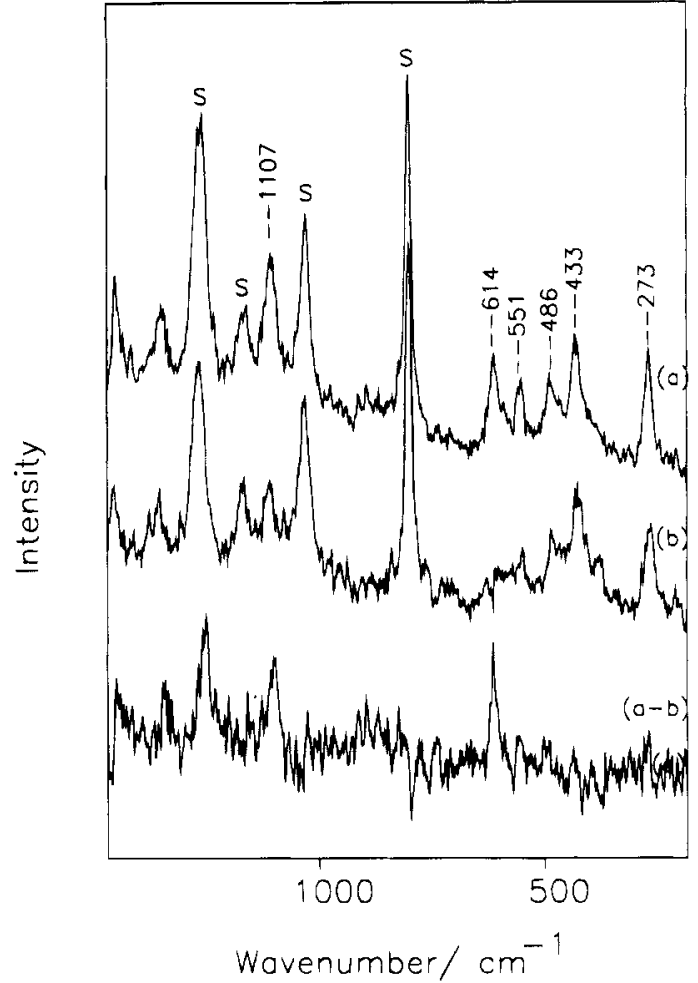

Figure 3. Two-color RR spectra from Figure 2 at shortest $(120 \mathrm{~ns}$, trace a) and longest ( $600 \mu \mathrm{s}$, trace b) pump-probe delays, showing the increased intensity of the $1264 \mathrm{~cm}^{-1}$ band at the shortest delay.

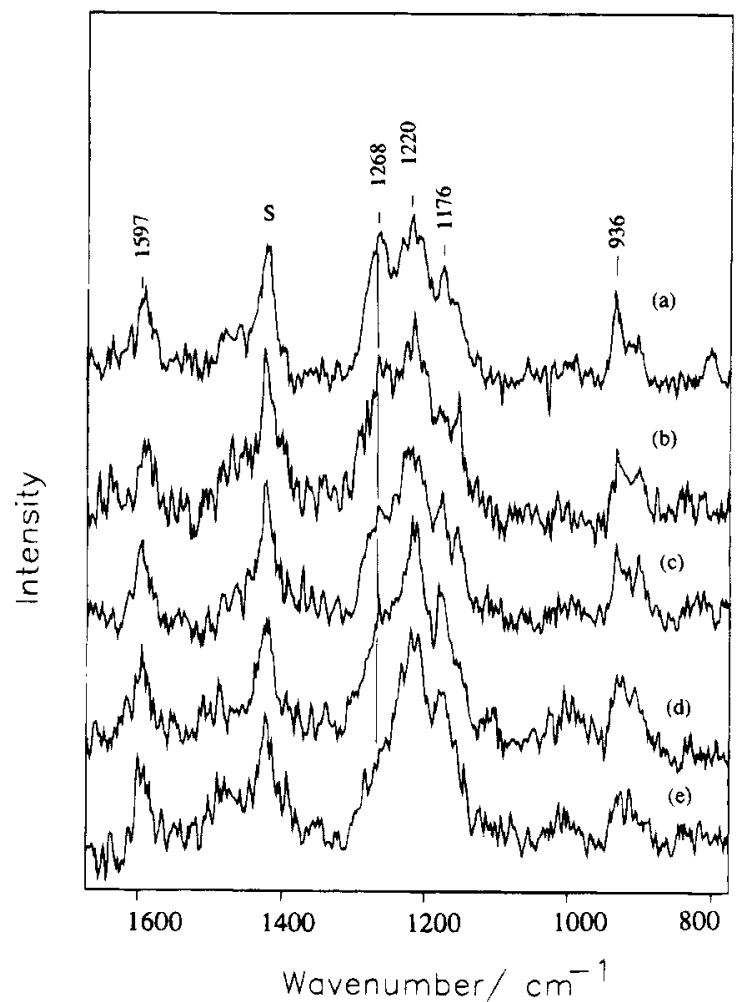

Figure 4. Two-color time-resolved resonance Raman study of $(\mathrm{CO})_{5} \mathrm{~W}=\mathrm{C}\left(\mathrm{OCH}_{2} \mathrm{CH}_{3}\right) \mathrm{C}_{6} \mathrm{H}_{5}$ in $\mathrm{CH}_{2} \mathrm{Cl}_{2}$ (ca. $10^{-3} \mathrm{~mol}$ $\mathrm{dm}^{-3}$ ): Pump $\lambda 351 \mathrm{~nm}$; probe $\lambda 420 \mathrm{~nm}$. Pump-probe time delays: (a) $100 \mathrm{~ns}$; (b) $500 \mathrm{~ns}$; (c) $1 \mu \mathrm{s}$; (d) $10 \mu \mathrm{s}$; (e) $50 \mu \mathrm{s}$.

and pulse-excited spectra as well as additional bands at $935 \mathrm{~cm}^{-1}$ and $1266 \mathrm{~cm}^{-1}$ in the spectra recorded under pulsed excitation at $355 \mathrm{~nm}$. Figure 4 shows two color $\mathrm{TR}_{3}$ spectra recorded for complex 3 in $\mathrm{CH}_{2} \mathrm{Cl}_{2}$ using

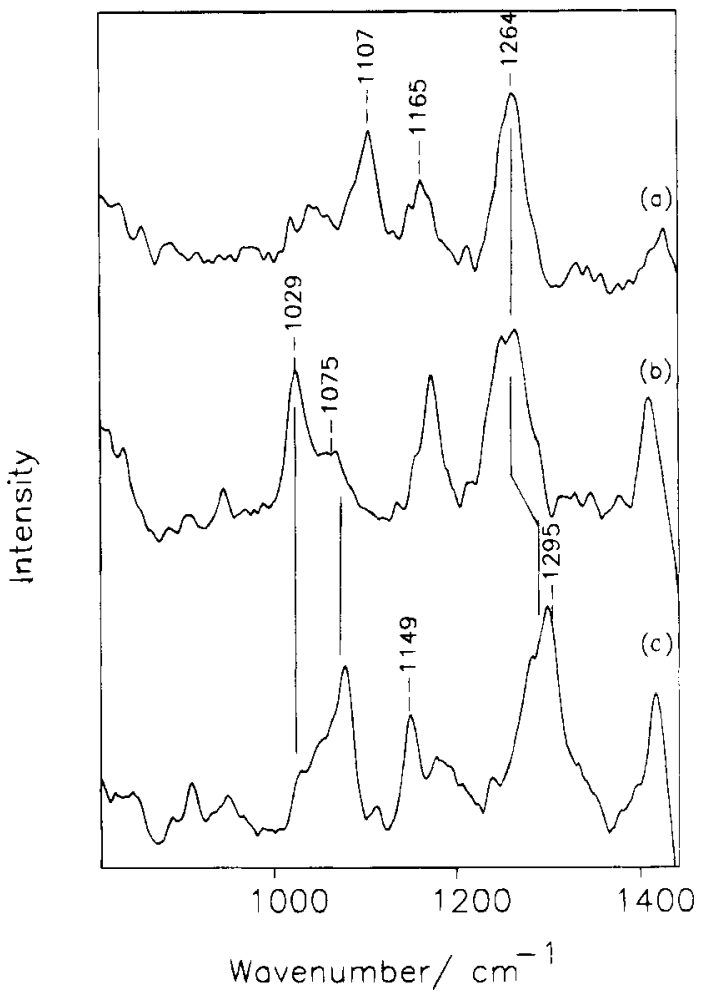

Figure 5. Influence of deuteriation on resonance Raman spectra of $(\mathrm{CO})_{5} \mathrm{~W}=\mathrm{C}\left(\mathrm{OCH}_{3}\right) \mathrm{CH}_{3}$, recorded at an excitation wavelength of $363.8 \mathrm{~nm}$ in $\mathrm{CH}_{2} \mathrm{Cl}_{2}$ (ca. $\left.10^{-3} \mathrm{~mol} \mathrm{dm}^{-3}\right)$ : (a) Undeuteriated species; (b) $(\mathrm{CO})_{5} \mathrm{~W}=\mathrm{C}\left(\mathrm{OCH}_{3}\right)\left(\mathbf{C D}_{3}\right)$; (c) $(\mathrm{CO})_{5} \mathrm{~W}=\mathrm{C}\left(\mathrm{OCD}_{3}\right)\left(\mathrm{CD}_{3}\right)$

a pump wavelength of $351 \mathrm{~nm}$ and a probe of $420 \mathrm{~nm}$. The transient nature of the 1266 and $935 \mathrm{~cm}^{-1}$ features is clear and the observed decay on a time scale of ca. 20 $\mu \mathrm{s}$ is consistent with flash photolysis measurements (Table 1).

For purposes of comparison RR spectra were also recorded for the $\mathrm{Cr}$ - analogue of $4,(\mathrm{CO})_{5} \mathrm{Cr}(\mathrm{OMe})(\mathrm{Ph})$. The spectra were generated using $\mathrm{CW}$ and pulsed excitation at $363.8 \mathrm{~nm}$ and $355 \mathrm{~nm}$ respectively. In the $\mathrm{CW}$-excited spectrum the primary features appear at $935 \mathrm{~cm}^{-1}, 997 \mathrm{~cm}^{-1}, 1235 \mathrm{~cm}^{-1}$ and $1270 \mathrm{~cm}^{-1}$, suggesting the presence of both anti and syn isomers. To establish that this was not simply due to the creation of a photostationary state, RR spectra were also recorded at an excitation wavelength of $457.9 \mathrm{~nm}$. At this wavelength negligible photochemical transformation to syn isomer would be expected yet the spectrum (not shown here) clearly displayed features characteristic of both species. NMR studies ${ }^{1}$ of $(\mathrm{CO})_{5} \mathrm{Cr}(\mathrm{OMe})$ $\mathrm{Ph}$ do in fact confirm the existence of both isomers in solution under ambient conditions.

Resonance Raman studies were also carried out on samples of 1 with deuteriated methyl and methoxy groups. The spectra recorded using $\mathrm{CW}$ excitation at $363.8 \mathrm{~nm}$ are displayed in Figure 5. When the $\mathrm{CH}_{3}$ group alone is deuteriated the band at $1264 \mathrm{~cm}^{-1}$ remains unshifted but additional features appear at $1029 \mathrm{~cm}^{-1}$ and $1075 \mathrm{~cm}^{-1}$. The spectrum recorded when the $\mathrm{OCH}_{3}$ and $\mathrm{CH}_{3}$ groups are both deuteriated shows bands near $1149 \mathrm{~cm}^{-1}$ and $1295 \mathrm{~cm}^{-1}$ as the primary features.

(c) Low Temperature Matrix Isolation Studies. When $(\mathrm{CO})_{5} \mathrm{WC}(\mathrm{OMe})(\mathrm{Ph})$ was deposited in an argon matrix at $20 \mathrm{~K}$ the IR spectrum exhibited $\mathrm{CO}$ stretching 
Table 3. IR Bands $\left(\mathrm{cm}^{-1}\right)$ for Carbene Complexes in $\mathrm{Ar}$ Matrix at $20 \mathrm{~K}$

\begin{tabular}{cc}
\hline complex & bands \\
\hline anti-(CO) $)_{5} \mathrm{WC}(\mathrm{OMe}) \mathrm{Ph}$ & $2074,1985,1950,1223,1212,1181$, \\
& $1149,993,876$ \\
syn-(CO) $)_{5} \mathrm{WC}(\mathrm{OMe}) \mathrm{Ph}^{a}$ & $2074,1985,950,1260,1191,1171,1128$, \\
& $936,917,878$ \\
anti-(CO $)_{5} \mathrm{WC}(\mathrm{OMe}) \mathrm{Me}$ & $2075,1985,1950,1456,1348,1255,1174$, \\
& 910,898 \\
syn-(CO $)_{5} \mathrm{WC}(\mathrm{OMe}) \mathrm{Me}^{a}$ & $2075,1985,1950,1340,1250,1175,1099$, \\
& 1081,998
\end{tabular}

${ }^{a}$ Bands observed after matrix irradiation (see text for details); features attributable to $\mathrm{CO}$ stretching modes are unshifted between anti and syn isomers.

modes at $2074 \mathrm{~cm}^{-1}, 1985 \mathrm{~cm}^{-1}$ and at $1950 \mathrm{~cm}^{-1}$ though with extensive matrix splitting. Several IR bands associated with the carbene moiety were also observed and are summarized in Table 3 . Irradiation of the matrix-isolated sample at $434 \mathrm{~nm}$, within the MLCT band $\left(\lambda_{\max }=404 \mathrm{~nm}\right)$ resulted in some intensity decrease and frequency shifts in the carbene IR bands as listed in Table 3 . Irradiation at $434 \mathrm{~nm}$ for $3 \mathrm{~h}$ resulted in $c a .70 \%$ conversion of the anti isomer as estimated from the observed decrease in intensity of the carbene band at $1223 \mathrm{~cm}^{-1}$. There were no apparent changes in the positions of the $\mathrm{CO}$ stretching modes though minor alterations could have been masked by the matrix splitting. As well as the changes in the carbene IR bands upon irradiation a blue shift in the MLCT band from $404 \mathrm{~nm}$ to $394 \mathrm{~nm}$ was observed. The results are consistent with earlier observations by Stufkens and co-workers on this complex in low temperature matrices ${ }^{2}$ and have been attributed to photoconversion of the anti to the syn isomer of $(\mathrm{CO})_{5} \mathrm{WC}$ $(\mathrm{OMe})(\mathrm{Ph})$. Irradiation of the sample in the matrix for $3 \mathrm{~h}$ within the MLCT band (394 nm) of the syn isomer failed to bring about any conversion back to the anti form, again consistent with previous work ${ }^{2}$.

The UV and IR spectra for the $(\mathrm{CO})_{5} \mathrm{WC}(\mathrm{OMe})(\mathrm{Me})$ complex deposited in an argon matrix at $20 \mathrm{~K}$ are shown in Figure 6. Irradiation within the MLCT band of the anti isomer $\left(\lambda_{\max } 368 \mathrm{~nm}\right)$ resulted in frequency shifts in several of the carbene IR bands, as shown in Table 3 and also a red shift in the UV spectrum from $368 \mathrm{~nm}$ to $375 \mathrm{~nm}$. There was no evidence for CO loss upon irradiation and no apparent changes in the $\mathrm{CO}$ stretching region, apart from matrix site splitting as in the case of $(\mathrm{CO})_{5} \mathrm{WC}(\mathrm{OMe})(\mathrm{Ph})$. The observations are consistent with formation of the syn isomer. Irradiation for ca. 1.5 $\mathrm{h}$ within the MLCT band of the anti isomer resulted in about $50 \%$ photoconversion as estimated from the decrease in the intensity of the carbene IR bands of the starting material. Interestingly in this case and in contrast to the situation with complex 4, matrix irradiation into the MLCT band of the syn isomer (ca. $1.5 \mathrm{~h}$ at $397 \mathrm{~nm}$ ) did result in regeneration of the anti isomer as judged by the grow-in of features in both the IR and UV/vis spectra (Table 3 ).

For both complexes the changes in the IR and UV spectra in the matrix experiments are consistent with the data recorded in the solution studies, indicating that the same process is being observed in both media.

\section{Discussion}

(1) Identification of the Transient. The timeresolved spectroscopic studies on the three carbene

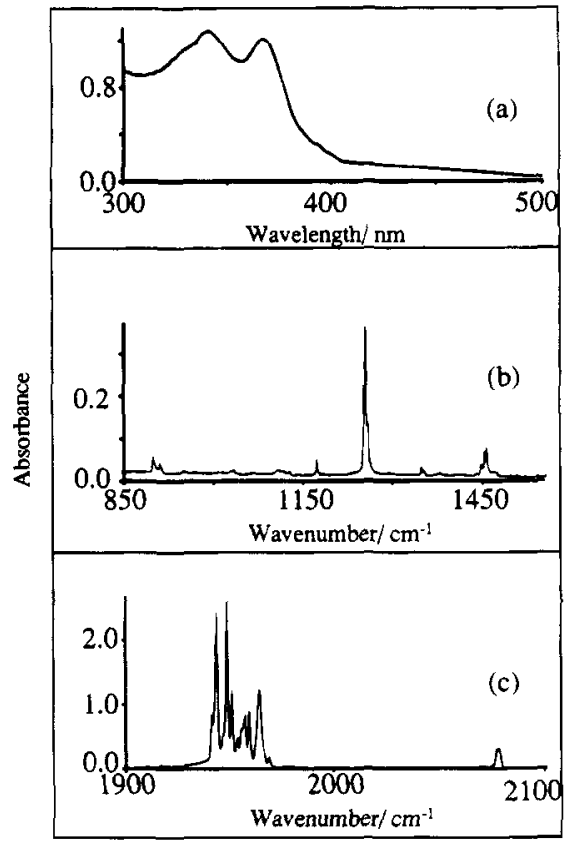

Figure 6. UV and IR spectra recorded for $(\mathrm{CO})_{5} \mathrm{WC}(\mathrm{OMe})$ (Me) upon deposition in an argon matrix at $20 \mathrm{~K}$ : (a) UV spectrum; (b, c) $v$ (carbene) and $v(\mathrm{CO})$ regions respectively. Arbitrary absorbance scales for (b) and (c) indicate relative band intensities.

complexes 1-3 in solution show that excitation into either LF or MLCT bands results in formation of the same single transient in $<10 \mathrm{~ns}$. The transient UV/vis and vibrational spectra for both the alkyl- and arylsubstituted carbenes closely resemble the corresponding spectra of the low temperature matrix photoproducts. The rate of decay of the transient is also independent of added $\mathrm{CO}$. The evidence supports the identification of the major photoreaction in these metal carbonyl carbene complexes in solution as an anti to syn isomerization (eq 1) about the $\mathrm{C}-\mathrm{OR}(\mathrm{R}=\mathrm{Me}, \mathrm{Et})$ carbene bond, as established by the matrix studies of Stufkens et al. for the Fischer carbene 4 and its $\mathrm{Cr}$ analogue. ${ }^{2}$ Free rotation about the $\mathrm{C}-\mathrm{OR}$ bond is inhibited by the partial double bond character, due to $\pi$ interaction between the oxygen lone pair and the carbene carbon $2 \mathrm{p}_{z}$ orbital.

(2) Comparative Kinetics and Spectroscopy of Aryl- and Alkyl-Substituted Carbenes in Solution. The flash photolysis studies show that the transient lifetimes (Table 1) for the alkyl-substituted carbenes are 1-2 orders of magnitude longer than for the arylsubstituted species. These differences are reflected in the activation enthalpies $51 \mathrm{~kJ} \mathrm{~mol}^{-1}$ and $37 \mathrm{~kJ} \mathrm{~mol}{ }^{-1}$ for the syn to anti thermal isomerization measured in cyclohexane solution for $(\mathrm{CO})_{5} \mathrm{WC}(\mathrm{OMe}) \mathrm{Me}$ and $(\mathrm{CO})_{5} \mathrm{WC}(\mathrm{OMe}) \mathrm{Ph}$, respectively. Steric interactions by the more bulky aryl group may be one factor influencing the thermal relaxation of the syn isomer. However this cannot be the only factor since previous flash photolysis studies $^{6}$ on the silyl-substituted carbene, $(\mathrm{CO})_{5} \mathrm{WC}$ $(\mathrm{OEt})\left(\mathrm{SiPh}_{3}\right)$, show the lifetime of the syn isomer to be similar to those determined for the sterically less crowded aryl-substituted carbenes. It appears that the aryl ring must also be exerting an electronic effect, possibly via an alteration during the isomerization of the extent of $\pi$ delocalization over the carbene ligand. This point is expanded upon below. The kinetic data 
in Table 1 also show that the rate of decay of the $s y n$ isomer is influenced by the solvent, being slower in more polar solvents for both alkyl- and aryl-substituted carbenes. This could be due to an increased stabilization of the syn isomer or a decrease in that of the transition state or more likely the result of some contribution from both.

The transient UV/vis spectra are significantly different for the alkyl- and aryl-substituted carbenes. The $\lambda_{\max }$ of the MLCT absorption for the syn isomer of the aryl-substituted complexes shifts to shorter wavelengths compared to the ground state spectrum while for the alkyl-substituted complex the corresponding spectra shift to longer wavelength. The spectral results in the latter case are consistent with those previously reported $^{6}$ for the silyl-substituted carbenes and a similar change in the relative stabilities of the HOMO and LUMO might have been expected upon photoisomerization of the closely related aryl-substituted carbenes. The shift to higher energy which is actually observed in the latter therefore suggests the operation of an additional factor in this case. As alluded to earlier, this might arise from a reduction in the degree of $\pi$ delocalization over the carbene moiety between the anti and $s y n$ isomers. The isomerization of $(\mathrm{CO})_{5} \mathrm{WC}(\mathrm{OR})\left(\mathrm{R}^{\prime}\right)$ according to eq 1 can involve not only rotation of the alkoxy group but an associated reorientation of $R^{\prime}$. When an aryl group rotates away from the plane of the carbene in order to minimise its steric interaction with the alkoxy group in the syn isomer there will be a reduction in the degree of $\pi$ interaction of the aryl ring with the carbene carbon $2 \mathrm{p}_{z}$ orbital in the syn isomer. ${ }^{12}$ This situation does not arise when $R^{\prime}$ is alkyl. Any effect of reorientation of the aryl group might be reflected in frequency changes in vibrational modes of the carbene.

Before discussing the resonance Raman spectra of 1-3 reference is made to the results obtained from studying the spectra of the deuterated analogs of 1 . The anti isomer of complex 1 exhibits significant shifts in the three bands in its RR spectrum at 1107, 1165 and $1264 \mathrm{~cm}^{-1}$ (Figure 5a) upon successive deuteriation of the $\left(\mathrm{CH}_{3}\right)$ and $\left(\mathrm{OCH}_{3}\right)$ groups (Figure $5 \mathrm{~b}, \mathrm{c}$, respectively). However attempts to assign the bands to specific vibrational modes by comparison of the frequency shifts observed upon deuteriation with those calculated on the basis of reduced mass considerations were inconclusive. It appears that mode coupling within the carbene moiety is involved but further speculation is unwarranted without additional data. Studies with isotopically labeled species in low temperature matrices are planned to aid band assignment.

The most significant feature of the resonance Raman data for these carbenes is the general similarity in the frequencies of modes assignable to the anti and syn isomers. This is illustrated for instance by the CW- and pulse-excited spectra for 1 (Table 1 and Figure 2). The notable lack of frequency shifts suggests that the change in position of the alkoxy group which characterises the isomerization between the anti and syn forms does not significantly perturb the vibrational modes of the com-

(12) $\mathrm{X}$-ray crystallographic studies ${ }^{14}$ on $(\mathrm{CO})_{5} \mathrm{CrC}(\mathrm{OMe})(\mathrm{Ph})$ show that in the solid state this complex exists as the anti isomer, with the phenyl ring lying at $90^{\circ}$ to the carbene plane so that there is no $\pi$ interaction between the phenyl ring and the carbene carbon $2 \mathrm{p}_{z}$ orbital However this situation may be different in solution where for instance crystal packing effects will not operate. plex. Available X-ray data, ${ }^{13}$ although for somewhat different systems, appear to be consistent with this conclusion.

The significant shift in the position of a mode between the two isomers which is observed occurs only for the aryl-substituted carbenes. The feature near $1235 \mathrm{~cm}^{-1}$ in the RR spectra of the anti forms of 2 and 3 shifts to $1266-1270 \mathrm{~cm}^{-1}$ in the respective syn isomer spectra. The analogous band $\left(1264 \mathrm{~cm}^{-1}\right)$ in the RR spectra of the alkyl-substitued complex 1 (Table 1 and Figure 2) shows no shift in frequency between the spectra of the two isomers. This band is associated ${ }^{2,15}$ with modes involving a substantial contribution from a $\left(\mathrm{C}_{\text {carbene }}{ }^{-}\right.$ $\mathrm{OMe}$ ) stretching motion, consistent with its significant intensity in both the RR and IR spectra of these complexes. As proposed above, the flash photolysis experiments suggest that the formation of the syn isomer of 2 and 3 requires a further rotation of the aryl group away from the plane of the carbene to minimize the steric interaction between the alkoxy group and the aryl ring. Stabilization of the syn isomer would then arise largely ${ }^{16}$ from oxygen lone pair donation into the carbon $2 \mathrm{p}_{z}$ orbital with a consequent increase in the $\mathrm{C}-\mathrm{OMe}$ bond order. Our spectral data are consistent with this although as stated earlier in relation to the results of the isotopic substitution studies, the vibrational spectra of the carbenes are complicated. That a shift in position of this band is only observed for the aryl-substituted carbenes ties in with the proposal that in this case an additional perturbation associated with phenyl ring reorientation is occurring in the course of the anti to syn isomerization.

(3) Comparative Spectroscopy of Aryl- and AlkylSubstituted Carbenes in Cryogenic Argon Matrices. Stufkens and co-workers reported that isomerization of $(\mathrm{CO})_{5} \mathrm{WC}(\mathrm{OMe})(\mathrm{Ph}), 4$, could be photochemically induced in one direction only, anti to syn, and we have confirmed this here. The reverse syn to anti isomerization was not observed, even following direct irradiation into the MLCT band of the syn isomer. The only photoreaction observed ${ }^{2}$ for the syn isomer of 4 in the matrix was $\mathrm{CO}$ dissociation via the LF state and it was suggested ${ }^{2}$ that the MLCT and LF states of 4 were so close in energy that reaction occurred preferentially from the more reactive LF state irrespective of the state initially populated. However, the matrix isolation studies reported in the present work show that for 1 the isomerization is photochemically reversible. In reported cases of "one-way" photoisomerization in stilbene-type molecules such as that observed in 1-(2-anthryl)-3,3dimethyl-1-butene the suggested explanation was that a local minimum exists on the excited state potential energy surface close to the geometry of the photochemically inert isomer. ${ }^{17}$ We propose here that in the arylsubsituted carbenes the first distortion in the MLCT state upon excitation of the syn isomer is a rotation of the aryl ring to a more conjugating position, the driving force being the resulting resonance stabilization. The relative rates of conversion of this localized thermally

(13) Schubert, U,; Ackermann, K.; Rustenmeyer, P. J. Organomet. Chem. 1982, 231, 323.

(14) Mills, O. S.; Redhouse, A. D. J. Chem. Soc. A 1968, 642.

(15) Fischer, E. O.; Massbol, A. Chem. Berichte 1967, 100, 2445

(16) Casey, C. P.; Burkhardt, T. J.; Bunnett, C. A.; Calabrese, J. C. J. Am. Chem. Soc. 1977, 99, 2127.

(17) Arai, T.; Karatsu, T.; Sakuragi, H.; Tokumaru, K. Tetrahedron Lett. 1983, 24, 2873. 
equilibrated excited state to either the anti or the syn forms will depend upon the relative dispositions of the three potential energy surfaces. The data suggest that in the present case decay occurs preferentially back into the potential energy well of the syn isomer; the MLCT state of the syn isomer is photochemically inert. For the anti isomer the solution studies suggest that some degree of conjugation extends over the carbene moiety in the ground state. Therefore, no significant rotation of the aryl ring need occur upon MLCT excitation. The initial excited state rapidly decays via rotation of the $\mathrm{C}-\mathrm{OMe}$ bond into a lower energy "twisted excited" state in which the orginal geometry of the complex is lost. From this state decay to either ground state isomer is possible. Hence in the aryl-substituted carbenes the MLCT excited state of the anti isomer is photochemically active to isomerization. Support for this explanation of "one way" photoisomerization for $(\mathrm{CO})_{5} \mathrm{WC}(\mathrm{OMe})$ $(\mathrm{Ph})$ comes from the matrix experiments on the alkylsubstituted carbene 1. The MLCT excited states of the anti and syn isomers of complex 1 are both active to isomerization. This consistent with the above proposed explanation for "one way" photoisomerization in the aryl-substituted case since "localized" stabilization of the MLCT excited state by increased conjugation cannot operate in complex 1 and both the syn and anti isomers would be expected to behave like the anti isomer of $(\mathrm{CO})_{5} \mathrm{WC}(\mathrm{OMe})(\mathrm{Ph})$.

\section{Summary and Conclusions}

1. The transient observed upon pulsed irradiation in solution into both the LF and MLCT band of these carbenes is assigned as the syn isomer. This assignment is supported by comparison with results from experiments carried out in cryogenic matrices. LF excitation provides no evidence in support of a transient arising from $\mathrm{CO}$ dissociation, although continuous $\mathrm{ir}$ radiation experiments ${ }^{3,5,6}$ show that the reaction should occur. Presumably the quantum yield for the process is so low that the transient is not detectable.

2. The lifetime of the syn isomer is dependent on the polarity of the solvent and on the nature of the ancillary $\left(R^{\prime}\right)$ group on the carbene carbon.
3. Distinctive photochemical behaviour is exhibited by the syn isomer of alkyl- and aryl-substituted carbenes. The most notable difference is that the MLCT excited state of the syn isomer of aryl-substituted carbenes is photoinert, while that of the alkyl-substituted complex leads to photoisomerization. These differences are consistent with the proposal that the isomerization of the aryl-substituted carbenes also involves a reorientation of the aryl ring to a less $\pi$-interacting position in the syn isomer.

4. There are clear parallels between anti-syn photoisomerization of metal carbenes ${ }^{18,19}$ as investigated in the present work and the extensively studied cis-trans photoisomerization of organic alkenes. ${ }^{20}$ However the novel feature which appears in the metal carbene complexes is that although the geometric change is centered on the carbene ligand it is not the direct result of an intraligand excitation process. The metal center is in effect acting as an intramolecular photosensitizer resulting in light absorption and the transfer of electron density onto the carbene ligand, thereby facilitating the isomerization.

Acknowledgment. We thank the U.K. Science \& Engineering Research Council for support (Grant GR/ F42980), Dr. A. W. Parker and Sue Tavender at the Central Laser Facility, Rutherford Appleton Laboratory, for assistance with two-laser $\mathrm{TR}_{3}$ experiments, and Professor R. N. Perutz for providing access to the matrix isolation apparatus in York. We also gratefully acknowledge several useful discussions with Dr. S. E. J. Bell and for some preliminary flash photolysis data on 1. We also thank Dr. Ala H. R. Al-Obaidi for assistance with processing of Raman spectra and for useful discussions.

\section{OM940449Z}

(18) (a) Kiel, W. A.; Lin, G-Y.; Constable, A. G.; McCormick, F. B.; Strouse, C. E.; Eisenstein, O.; Gladysz, J. A. J. Am. Chem. Soc. 1982, 104, 4865. (b) McCormick, F. B.; Kiel, W. A.; Gladysz, J. A. Organometallics 1982, $1,405$.

(19) Voran, S.; Blau, H.; Wolfgang, M.; Schubert, U. J. Organomet. Chem. 1982, 232(C), 33.

(20) Allen, M. T.; Whitten, D. G. Chem. Rev. 1989, 89, 1691. 